\title{
Resistência de genótipos de feijoeiro a Bemisia tabaci biótipo B
}

\author{
Lucas Castro Torres $\left({ }^{1 *}\right)$, Brígida de Souza $\left({ }^{2}\right)$; André Luiz Lourenção ( $\left.{ }^{3}\right)$; Marlice Botelho \\ Costa ( $\left.{ }^{2}\right)$; Bruno Barbosa Amaral ( $\left.{ }^{2}\right)$; Sérgio Augusto Morais Carbonell ( ${ }^{3}$ ); Alisson Fernando \\ Chiorato ( $\left.{ }^{3}\right)$; Ricardo Lima Tanque $\left({ }^{2}\right)$ \\ (') Universidade Católica Dom Bosco, 79117-900 Campo Grande (MS), Brasil. \\ (2) Universidade Federal de Lavras, Departamento de Entomologia, 37200-000 Lavras (MG), Brasil. \\ (3) Instituto Agronômico, Centro de Pesquisa e Desenvolvimento de Fitossanidade, 13075-630 Campinas (SP), Brasil. \\ $\left({ }^{*}\right)$ Autor correspondente: torreslct80@yahoo.com.br
}

Recebido: 11/jul./2012; Aceito: 31/ago./2012

\section{Resumo}

O estudo de genótipos de feijoeiro resistentes à mosca-branca Bemisia tabaci (Genn.) biótipo B (Hemiptera: Aleyrodidae) é de grande importância devido aos danos ocasionados por essa praga à cultura. Neste trabalho, foram estudados a atratividade para adultos, a preferência para oviposição em testes com e sem chance de escolha, o ciclo ovo-adulto e o tipo e número de tricomas presentes nos folíolos. Os experimentos foram realizados em casa de vegetação avaliando-se, inicialmente, cem genótipos de feijoeiro. A resistência do tipo não-preferência para alimentação e/ou antibiose foi observada nos genótipos ARC-3, IAC-Alvorada e Canário 101, sendo a emergência de adultos fortemente influenciada pelos genótipos. Também se observou correlação negativa moderada entre o número de ovos e o número de tricomas glandulares, e correlação positiva muito forte entre o número de ovos e o número de tricomas tectores unciformes.

Palavras-chave: Aleyrodidae, mosca-branca, não-preferência, Phaseolus vulgaris.

\section{Resistance of bean genotypes to Bemisia tabaci biotype B}

\section{Abstract}

The study of bean genotypes resistant to the whitefly Bemisia tabaci (Genn.) B biotype (Hemiptera: Aleyrodidae) has been of great importance due to the damage caused by this pest. In this research, bean genotypes were evaluated regarding attractiveness to whitefly adults, the preference for oviposition in free-choice and non choice tests, egg-to-adult development time and characterized for the presence, type and number of trichomes. The experiments were carried out under greenhouse conditions initially evaluating 100 bean genotypes. The non-preference type of resistance for feeding and/or antibiosis was observed in the genotypes ARC-3, IAC-Alvorada and Canário 101, and the emergence of adults was strongly influenced by the genotypes. It was also observed a moderate negative correlation between the number of eggs and the number of glandular trichomes, as well as a very strong positive correlation between the number of eggs and the number of unciform non-glandular trichomes.

Key words: Aleyrodidae, silverleaf whitefly, nonpreference, Phaseolus vulgaris.

\section{INTRODUÇÃO}

A mosca-branca B. tabaci biótipo B causa grandes prejuízos à cultura do feijoeiro, afetando sua produtividade. Os danos ocasionados são devidos, principalmente, à transmissão do vírus do mosaico-dourado-do-feijoeiro (Bean golden mosaic virus - BGMV), podendo ser considerada a principal praga da cultura e tornando-se fator limitante da produção em várias regiốes, durante a safra da seca (Bianchini et al., 1981; YoKoyama, 1996).

Os danos causados pelo BGMV podem variar conforme a cultivar plantada, a porcentagem de infecção pelo vírus e o estádio de desenvolvimento da planta por ocasiấo da incidência da doença (Almeida et al., 1984). Ainda, de acordo com FARIA et al. (1996), as perdas oriundas da infecção por esse vírus podem variar de 30 a 100\%, o que é influenciado pelas condições ambientais e pela presença de hospedeiros alternativos. Além dos danos indiretos causados pela transmissão de vírus, as moscas-brancas podem causar danos diretos, podendo-se citar a retirada de seiva do floema e inoculação de toxinas que provocam alteraçóes no desenvolvimento vegetativo e reprodutivo da planta, o que pode reduzir a produtividade e a qualidade dos grãos.

Considerando esses danos e também devido ao fato de B. tabaci biótipo B desenvolver resistência a vários 
grupos de inseticidas, tem-se estudado o uso de genótipos resistentes a essa praga como forma de reduzir os prejuízos. Diversas características como presença, tipos e tamanho de tricomas, compostos químicos presentes na planta, coloração geral, entre outras características, podem conferir algum tipo de resistência ao vegetal. No entanto, atualmente, poucos são os trabalhos que avaliaram a resistência de feijoeiros a $B$. tabaci biótipo $\mathrm{B}$, bem como ao mosaico-dourado.

Considerando-se a necessidade de se identificar cultivares de feijoeiro resistentes à mosca-branca, avaliou-se no presente trabalho, um grupo de genótipos que representa os diferentes centros de origem da espécie e com, portanto, grande variabilidade genética. Teve-se como objetivo selecionar genótipos resistentes a $B$. tabaci biótipo $\mathrm{B}$ com base na atratividade para adultos, preferência para oviposição e desenvolvimento ovo-adulto, em condiçóes de casa de vegetação.

\section{MATERIAL E MÉTODOS}

\section{Criação de manutenção de Bemisia tabaci biótipo $\mathrm{B}$}

A população inicial de moscas-brancas foi proveniente do Instituto Agronômico (IAC) e previamente identificada pela Dr. ${ }^{a}$ Judith K. Brown, da Universidade do Arizona, EUA, como B. tabaci biótipo B. Recentemente, confirmou-se a identidade de insetos dessa criação por meio de RAPD (Fontes et al., 2010). Para manutenção da mosca-branca, utilizaram-se plantas de couve 'Manteiga da Geórgia', em casa de vegetação (Torres et al., 2007).

\section{Genótipos avaliados}

As sementes foram obtidas no Instituto Agronômico (IAC), sendo parte do Banco Ativo de Germoplasma dessa instituição. Os genótipos selecionados, no total de cem, representaram os mais diversos grupos de feijoeiros, sendo alguns nacionais e outros de diversos países, o que conferiu grande variabilidade genética ao germoplasma avaliado. Dos genótipos utilizados, 44 têm algum nível de resistência ao mosaico-dourado-do-feijoeiro sendo eles: IAPAR-72, MD-806, IAPAR-44, ARC-1, ARC-2, ARC-3, ARC-4, IAPAR-14, DOR390, DOR-391, DOR-476, DOR-482, IAC-UNA, RAZ-56, RAZ-49, RAZ-43, RAZ-59, RAZ-55, IACTybatã, IAC-Carioca ETÉ, DOR-202, IAPAR-57, Gen 96A98-13-1-52-1, Gen 96A100-6-1-53-1, Gen96A3-P1-1-1, Gen 96A98-5-1-1-55, Gen 96A453-51-52-1, Gen 96A98-15-3-52-1, BRS-Pontal, BRSRequinte, Core 194 (184), Gen 99TG 50-47, Gen 99TGR 60-9, Gen 99TG 8-83, Gen 99TG 34-50, LP
02-130, Z-28, LP01-38, LP 9979, LP 98-122, CV-48, MD Aurora, Branquinho, Gen 96A101.

Foram, ainda, utilizados outros 56 genótipos, entre eles materiais cultivados em países como Costa Rica, Honduras, Guatemala, México, Venezuela e Holanda, além de materiais cultivados no Brasil, a saber: Guatemala-2226, Bico de Ouro, Leg. Rosinha, Sacavem-580, 60 Dias, Aete-2, Vermelho de Minas, Manteiguinha, Branco-119, Coco Blanchi, Pirata-1, Venezuela-42-5-1, México-309, México-435, Preto Uberabinha, Costa Rica, Honduras-32, Preto-196, Black Turtle Soup Bean, Safira, BB Lake, A-ICA-TUI, Canário-101, B. Porrillo-70, Copinho Grande Preto, Cavalo Amarelo, México-12, Carioca MG, PI-310724, Puebla-152 (CIAT), Ouro Negro, Gordo Branco, Rico-23, Mulata Gorda, Pijão, IAPAR-65, IAPAR-80, Tarumã, Conejo, Ovo de Codorna Tyunaga Vermelho, Bat-332, RIZ-30, AB-136, PI-207262, G2333, Xan12, Moruna-80, Carioca Lustroso (Itaberá), Contender, Mercana e, ainda, BRS Horizonte, Radiante, BRS Cometa, Talismã, Majestoso e Pérola.

\section{Seleção inicial dos genótipos quanto à preferência para oviposição e atratividade para adultos de Bemisia tabaci biótipo B}

Com o objetivo de se determinar, entre os cem materiais selecionados, quais apresentavam não-preferência para oviposição e menor atratividade para adultos de B. tabaci biótipo $\mathrm{B}$, foi feita uma seleção inicial. As plantas foram semeadas em vasos com capacidade para 2 litros contendo substrato composto por terra-de-barranco e esterco bovino curtido na proporção de 3:1 e devidamente adubadas conforme indicaçẫo para a cultura. Foram utilizadas três sementes por vaso e, posteriormente, efetuado o desbaste deixando-se duas plântulas em cada um deles. As plantas foram utilizadas quando atingiram o estágio de desenvolvimento IV-1 (primeira folha trifoliada completamente expandida) (AZAEL, 1976), e antes de se iniciarem os testes, foram retiradas as folhas cotiledonares de cada uma delas.

Nesse experimento, ainda foram utilizados 50 vasos com capacidade de 1 litro, preenchidos com o mesmo substrato descrito anteriormente, nos quais foram plantadas sementes da cultivar Valente, que serviu como foco de infestação. Essas plantas também foram utilizadas no estágio de desenvolvimento IV-1 e, para que fossem infestadas com os adultos da mosca-branca, permaneceram dentro da criação de manutenção por 24 horas. Posteriormente, esses vasos-foco, com cerca de mil adultos cada um, foram transferidos para a casa de vegetação onde foi realizado o experimento. Esses vasos foram dispostos de forma equidistante em relação àqueles contendo os genótipos e utilizados na proporçấo de 1:4 respectivamente. Nesse ambiente, permaneceram por 
um período de 72 horas, tempo suficiente para que os adultos da mosca-branca pudessem se deslocar aleatoriamente em busca dos genótipos preferidos.

O delineamento utilizado foi o Lattice (PBIB) (Cochran e Cox, 1992), com duas repetiçóes (Simple Lattices), utilizando-se o programa MSTAT-C, versão 2.10 (Koenler, 1999). Cada uma das repetições foi constituída por dez blocos em linha e dez colunas por bloco onde foram sorteados os cem genótipos, utilizando-se o programa estatístico Sisvar.

Em cada uma das 200 plantas utilizadas neste teste foram contados os adultos presentes na primeira folha trifoliada completamente expandida. Essa contagem foi feita às 24, 48 e 72 horas após o início da infestação, utilizando-se um pequeno espelho para facilitar a visualizaçáo dos insetos na face abaxial da folha. $\mathrm{O}$ uso desse método visou evitar a movimentação da folhagem, o que provocaria o abandono da planta pelos adultos. Após a avaliação realizada com 72 horas da infestação, as plantas foram levadas para laboratório onde, sob microscópio estereoscópico, foram contados os ovos presentes em uma área de $2 \times 2 \mathrm{~cm}$ na regiáo central da face abaxial de cada folíolo, obtendo-se o número de ovos por $\mathrm{cm}^{2}$. O teste foi realizado em casa de vegetação, com temperatura de $25,1 \pm 0,2^{\circ} \mathrm{C}$, umidade relativa de $80,4 \pm 0,7 \%$.

\section{Atratividade e preferência para oviposição nos genótipos selecionados}

Avaliaram-se a atratividade e a preferência para oviposição em testes com e sem chance de escolha em 20 genótipos selecionados na seleção inicial. As plantas foram cultivadas em vasos de polietileno com capacidade para 1 litro, contendo substrato composto por terra-de-barranco e esterco bovino curtido na proporção de 3:1. Foi utilizada apenas uma planta por vaso, efetuando-se a adubação conforme recomendação para a cultura. As plantas foram mantidas sobre bancadas em casa de vegetação isolada e irrigadas diariamente até atingirem o estágio de desenvolvimento IV-1 (AzAEL, 1976), quando se realizaram os testes.

Nos experimentos de preferência para oviposição com e sem chance de escolha foram utilizadas oito plantas de cada genótipo (uma planta por vaso) para cada um dos ensaios. Em ambos os testes, os adultos de mosca-branca foram coletados na criação de manutenção com aspirador entomológico e a contagem dos insetos feita com auxílio de contador manual. Obteve-se, assim, um número constante de indivíduos para serem liberados em cada gaiola utilizada nos testes.

Para o teste de atratividade e preferência para oviposição com chance de escolha, foram utilizadas oito gaiolas de $1,40 \mathrm{~m}$ de comprimento, $0,95 \mathrm{~m}$ de largura e $0,95 \mathrm{~m}$ de altura, confeccionadas com tecido voile. Em cada uma delas foram colocados os vasos contendo uma planta de cada genótipo de feijoeiro e liberados 2000 adultos de mosca-branca, mantendo-se uma proporção de cem indivíduos por planta, conforme método descrito por Toscano et al. (2002). Nesse ambiente, as plantas foram deixadas durante três dias para que as moscas-brancas ovipositassem. Foram contados os adultos presentes em toda a área da face abaxial da primeira folha trifoliada completamente expandida, após 72 horas do início da infestação, por meio de espelho. Após a contagem dos adultos, as plantas foram levadas ao laboratório para contagem dos ovos sob estereoscópio e obtençáo do número de ovos por $\mathrm{cm}^{2}$. Foi vistoriada, em cada planta, a primeira folha trifoliada completamente expandida, e na face abaxial de cada folíolo foram contados os ovos depositados.

O delineamento utilizado nos testes foi o de blocos casualizados com 20 tratamentos (genótipos) e oito blocos (gaiolas). Os testes foram realizados em casa de vegetaçáo, a uma temperatura média de $24,2 \pm 0,3{ }^{\circ} \mathrm{C}$ e umidade relativa média de $79,6 \pm 1,6 \%$. Os dados obtidos foram submetidos à análise de variância utilizando-se o programa estatístico Sisvar, transformando-os para $\sqrt{x}$. O teste de Tukey a 5\% de significância foi usado para a comparação entre as médias.

Para o teste sem chance de escolha, foram utilizadas 56 gaiolas com $60 \mathrm{~cm}$ de altura e $40 \mathrm{~cm}$ de diâmetro, confeccionadas com tecido voile. Avaliaram-se sete genótipos, considerando-se os cinco menos e os dois mais ovipositados no teste com chance de escolha. Para cada um dos sete genótipos foram utilizadas oito gaiolas, em cujo interior foi colocada apenas uma planta e liberados cem adultos de mosca-branca conforme método descrito por Toscano et al. (2002). As plantas permaneceram durante três dias no interior das gaiolas, expostas à oviposição pelas moscas-brancas. A seguir, foram levadas ao laboratório para a contagem dos ovos presentes na face abaxial de cada folíolo das duas primeiras folhas trifoliadas completamente expandidas.

O delineamento foi o inteiramente casualizado, com sete tratamentos (genótipos) e oito repetiçóes (plantas). Este teste foi realizado em casa de vegetação, à temperatura média de $24,7 \pm 0,2{ }^{\circ} \mathrm{C}$ e umidade relativa média de $82,3 \pm 1,7 \%$. Os dados obtidos foram submetidos à análise de variância, utilizando-se o programa estatístico Sisvar, transformando-os para $\sqrt{x+1}$, e usando-se o teste de Tukey a 5\% de significância para a comparação das médias.

\section{Desenvolvimento ovo-adulto de B. tabaci biótipo $B$ nos genótipos selecionados}

Neste experimento, também foram utilizados os sete genótipos avaliados no teste sem chance de escolha. Foram mantidas duas plantas por vaso, infestadas 35 dias após a semeadura, quando atingiram o estágio de desenvolvimento IV-3 (AzAEL, 1976). 
Para a obtenção de ovos, as plantas foram colocadas na criaçáo de B. tabaci biótipo B por 12 horas. Após esse período, retiraram-se os adultos presentes nas folhas. Em laboratório, as plantas foram examinadas sob estereoscópio para a eliminação do excesso de ovos, deixando-se apenas um ovo de coloração amarelo-claro por folíolo, nas folhas com melhor aspecto visual. Em cada planta avaliaram-se cinco ovos. À medida que as ninfas eclodiam e se fixavam, foi feita uma marca com caneta para retroprojetor, próxima a cada uma delas, para facilitar sua localização. As avaliações foram realizadas diariamente, sempre no mesmo horário, observando-se a eclosão e as mudanças de ínstar e obtendo-se, assim, a duração do período embrionário, do período ninfal e do período total de ovo a adulto, bem como a viabilidade dos ovos e a sobrevivência na fase de ninfa.

O experimento foi desenvolvido em casa de vegetação com temperatura de $25,4 \pm 0,2{ }^{\circ} \mathrm{C}$, umidade relativa de $82,2 \pm 0,9 \%$, utilizando-se o delineamento inteiramente casualizado com sete tratamentos (genótipos) e seis repetiçôes, cada planta constituída por dez subamostras (cinco ovos por planta).

Os dados referentes à duração das fases de ovo e ninfal e o período de ovo a adulto, bem como os dados de emergência de adultos foram analisados, utilizando-se o software estatístico R versão 2.10.1 (R Development Core Team, 2009). Nos casos em que o teste F da ANOVA foi significativo, o teste de Tukey a 5\% de significância foi usado para a comparação entre as médias.

\section{Tipo e número de tricomas e correlação com teste de preferência para oviposição}

Os genótipos utilizados neste estudo foram os sete avaliados nos teste sem chance de escolha e desenvolvimento ovo-adulto. Para o preparo das lâminas com o tecido foliar, utilizaram-se dez folíolos totalmente desenvolvidos de cada genótipo, retirados das plantas usadas nos testes de não-preferência para oviposição. Logo após serem destacados das plantas, os folíolos foram colocados em recipientes plásticos contendo álcool 70\%, nos quais permaneceram por 30 dias. Após esse período, procedeu-se a montagem de lâminas semipermanentes. De cada folíolo foram retirados quatro cortes da epiderme abaxial, os quais foram imediatamente colocados em água destilada e, depois, em hipoclorito de sódio na concentração de $2 \%$ para a clarificação. Nesse meio, permaneceram por cinco minutos quando foram novamente colocados em água destilada por mais cinco minutos. Posteriormente, os cortes foram colocados sobre a lâmina com o corante safranina $0,1 \%$ em água + glicerina e cobertos com a lamínula, a qual foi vedada com esmalte para unha. Foram montadas dez lâminas de cada genótipo, contendo, cada lâmina, quatro cortes, e observado um campo por corte, determinando-se a presença, o número e o tipo de tricoma. $\mathrm{O}$ material foi observado em estereoscópio com aumento de dez vezes, sendo contados os tricomas presentes em um campo de dimensão correspondente a $6,3 \times 3,2 \mu \mathrm{m}$. Foi utilizado o delineamento inteiramente casualizado com sete tratamentos (genótipos) e dez repetiçôes (lâminas), constituídas por quatro cortes cada uma.

Os dados obtidos foram submetidos à análise de variância, utilizando-se o programa estatístico Sisvar, sendo a comparação entre as médias realizada pelo teste de Tukey a 5\% de significância. Foi realizada análise de correlação entre o número de ovos colocados em sete genótipos, no teste de preferência para oviposição com chance de escolha e o número de tricomas presentes na superfície abaxial das folhas desses genótipos.

\section{RESULTADOS E DISCUSSÃO}

\section{Seleção inicial dos genótipos quanto à preferência para oviposição e atratividade para adultos de Bemisia tabaci biótipo B}

Entre os cem genótipos avaliados, 20 foram selecionados, com base no menor número de ovos, para dar continuidade às avaliaçôes (Tabela 1). Considerandose os cem genótipos (dados não tabelados) constata-se que o número médio de ovos $/ \mathrm{cm}^{-2}$ nesses genótipos variou de 7,5 (IAC Alvorada) a 56,7 ovos $/ \mathrm{cm}^{-2}$ (IAC Centauro) e as médias ajustadas pelo programa estatístico, as quais foram usadas na seleção dos genótipos, variaram de $-2,1$ ovos $/ \mathrm{cm}^{-2}$ (IAC Alvorada) a 42,0 ovos $/ \mathrm{cm}^{-2}$ (IAC Centauro e Carioca Lustroso). As médias ajustadas dos genótipos não selecionados variaram de 43,5 ovos $/ \mathrm{cm}^{-2}$ a 1217,2 ovos $/ \mathrm{cm}^{-2}$ (Mulata Gorda).

Os genótipos Gen 96A98-13-1-52-1 e Gen 96A101 foram registrados como cultivares em 2008 (CARBONELL et al., 2008a,b), sendo referidos atualmente como 'IACAlvorada' e 'IAC-Centauro' respectivamente.

Quanto ao menor número de adultos atraídos, os genótipos que se destacaram foram: IAC-Alvorada, G2333, GEN 96A98-15-3-52-1, PI 207262, BRS Pontal, IAPAR 44, Carioca MG, IAPAR 14, Canário 101, DOR 482, Mercana, BRS Requinte, XAN 12, DOR 390, IAC Carioca ETÉ, B. Porrillo 70, ARC-1, MD 806, Honduras 32 e ARC-3. O número médio de adultos/folíolo nesses genótipos variou de 16,7 (PI 207262) a 38,7 (ARC-1) e as médias ajustadas pelo programa estatístico, as quais foram usadas para selecionar os genótipos, variaram de 9,2 (IAC Alvorada) a 27,8 adultos/folíolo (ARC-3). As médias ajustadas dos genótipos não selecionados variaram de 28,7 adultos/folíolo a 333,9 adultos/folíolo (Mulata Gorda). 
Confrontando os resultados obtidos nas contagens de ovos e de adultos atraídos, onze genótipos foram comuns a ambas as avaliaçóes: IAC-Alvorada, Gen 96A98-15-352-1, G2333, BRS Pontal, Carioca MG, ARC 1, Canário 101, IAPAR 14, ARC 3, BRS Requinte e IAPAR 44. Assim, optou-se por usar todos os vinte genótipos selecionados no teste de preferência para oviposição, visto que, o fato de o adulto estar presente na folha no momento da avaliaçáo não assegura que ele tenha se alimentado ou mesmo ovipositado naquele hospedeiro.

\section{Atratividade e preferência para oviposição nos genótipos selecionados}

No teste com chance de escolha, os menores números de adultos foram observados em 'IAC-Centauro', 'MD Aurora' e G2333, com, respectivamente, 25,0; 25,7 e 28,0 exemplares por folíolo, sendo os mais atrativos Arc3, 'Canário 101' e 'BRS Requinte', com 182,4; 106,3 e 73,8 adultos atraídos respectivamente (Tabela 1). Entre os genótipos com comportamento intermediário, as médias variaram de 31,2 a 67,6 adultos por folíolo.

Avaliando a atratividade para adultos da mosca-branca B. tabaci biótipo B, em laboratório, sob infestação de cem

Tabela 1. Número médio de adultos por folíolo e de ovos por $\mathrm{cm}^{2}( \pm \mathrm{EP})$ de Bemisia tabaci biótipo B em genótipos de feijoeiro, em teste com chance de escolha, em casa de vegetaçáo. $T=24,2$ $\pm 0,25{ }^{\circ} \mathrm{C}$; UR $=79,6 \pm 1,60 \%$

\begin{tabular}{|l|llll|}
\hline Genótipo & $\begin{array}{c}\text { Número de } \\
\text { adultos/folíolo }\end{array}$ & \multicolumn{2}{c}{$\begin{array}{c}\text { Número de } \\
\text { ovos/cm }\end{array}$} \\
\hline IAC-Centauro & $25,0 \pm 3,1$ & $\mathrm{a}$ & $14,2 \pm 2,6$ & $\mathrm{ab}$ \\
\hline MD Aurora & $25,7 \pm 4,1$ & $\mathrm{a}$ & $14,4 \pm 2,3$ & $\mathrm{ab}$ \\
\hline G2333 & $28,0 \pm 4,4$ & $\mathrm{a}$ & $19,7 \pm 3,4$ & $\mathrm{abc}$ \\
\hline IAC-Alvorada & $31,2 \pm 5,3$ & $\mathrm{ab}$ & $14,9 \pm 2,6$ & $\mathrm{ab}$ \\
\hline BRS-Horizonte & $32,5 \pm 5,6$ & $\mathrm{ab}$ & $12,7 \pm 2,3$ & $\mathrm{a}$ \\
\hline IAPAR-57 & $34,1 \pm 7,0$ & $\mathrm{ab}$ & $18,1 \pm 3,7$ & $\mathrm{ab}$ \\
\hline IAPAR-14 & $36,6 \pm 8,9$ & $\mathrm{ab}$ & $25,9 \pm 6,3$ & $\mathrm{abc}$ \\
\hline ARC-1 & $40,8 \pm 8,1$ & $\mathrm{ab}$ & $22,4 \pm 5,5$ & $\mathrm{abc}$ \\
\hline IAPAR-44 & $42,8 \pm 6,3$ & $\mathrm{ab}$ & $31,2 \pm 4,8$ & $\mathrm{abc}$ \\
\hline Carioca Lustroso & $48,8 \pm 9,2$ & $\mathrm{ab}$ & $24,6 \pm 4,0$ & $\mathrm{abc}$ \\
\hline Itaberá) & $50,1 \pm 6,4$ & $\mathrm{ab}$ & $21,4 \pm 3,1$ & $\mathrm{abc}$ \\
\hline Carioca MG & $50,3 \pm 13,7$ & $\mathrm{ab}$ & $25,2 \pm 6,4$ & $\mathrm{abc}$ \\
\hline Gen 96A98-15-3-52-1 & $53,9 \pm 7,8$ & $\mathrm{abc}$ & $27,4 \pm 4,6$ & $\mathrm{abc}$ \\
\hline BRS Pontal & $59,0 \pm 7,6$ & $\mathrm{abc}$ & $43,2 \pm 5,7$ & $\mathrm{~cd}$ \\
\hline RAZ 55 & $63,7 \pm 7,4$ & $\mathrm{abc}$ & $37,3 \pm 5,8$ & $\mathrm{bcd}$ \\
\hline B. Porrilo 70 & $64,9 \pm 7,9$ & $\mathrm{abc}$ & $35,9 \pm 7,7$ & $\mathrm{abc}$ \\
\hline IAC UNA & $67,6 \pm 9,9$ & $\mathrm{abc}$ & $30,5 \pm 4,3$ & $\mathrm{abc}$ \\
\hline RAZ 56 & $73,8 \pm 11,3$ & $\mathrm{bc}$ & $26,3 \pm 4,4$ & $\mathrm{abc}$ \\
\hline BRS Requinte & $106,3 \pm 10,2$ & $\mathrm{~cd}$ & $71,1 \pm 9,9$ & $\mathrm{~d}$ \\
\hline Canário 101 & $182,4 \pm 33,7$ & $\mathrm{~d}$ & $45,7 \pm 8,4$ & $\mathrm{~cd}$ \\
\hline ARC-3 & 27,41 & & 29,75 & \\
\hline CV (\%) & 10,561 & & 6,424 & \\
\hline F & 0,000 & & 0,000 & \\
\hline P & & & & \\
\hline
\end{tabular}

Médias seguidas pela mesma letra, na coluna, năo diferem entre si pelo teste de Tukey $(\mathrm{p}>0,05)$. adultos por planta durante quatro dias, ORIANI et al. (2005a) também detectaram diferenças significativas de atratividade, com médias entre 11,6 adultos/planta no genótipo G13028 e 135,5 adultos / planta no genótipo Bolinha.

Ainda no teste com chance de escolha, 'BRSHorizonte', 'IAC-Centauro', 'MD Aurora', 'IACAlvorada' e 'IAPAR-57' se destacaram com o menor número de ovos $\left(12,7 ; 14,2 ; 14,4 ; 14,9\right.$ e 18,1 ovos $/ \mathrm{cm}^{-2}$ respectivamente), enquanto 'Canário 101', ARC-3 e RAZ 55 foram os genótipos em que se constatou maior oviposição $\left(71,1 ; 45,7\right.$ e 43,2 ovos $/ \mathrm{cm}^{-2}$ respectivamente) (Tabela 1). No grupo intermediário, as médias variaram de 19,7 a 37,3 ovos $/ \mathrm{cm}^{-2}$.

No genótipo B. Porrillo 70 constatou-se a média de 37,3 ovos $/ \mathrm{cm}^{-2}$ (Tabela 1 ), diferindo do resultado obtido por Oriani et al. (2005b), para o mesmo genótipo, que obtiveram 3,1 ovos $/ \mathrm{cm}^{2}$ em temperatura de $23 \pm 2{ }^{\circ} \mathrm{C}$, UR de $70 \pm 10 \%$ e fotofase de 13 horas. No entanto, a diferença nesses resultados pode ser justificada pelo nível de infestação que foi equivalente a 33,3 adultos por folíolo (100 adultos por planta) no presente trabalho, enquanto no trabalho de Oriani et al. (2005b) utilizaram-se 2,5 adultos por folíolo (500 adultos liberados em gaiola contendo 200 folíolos, sendo 20 de cada um dos 10 genótipos).

Em trabalho realizado por Oriani et al. (2005b), nas condiçóes citadas anteriormente, obtiveram-se médias variando de 54,9 (Arc 5s) a 1194,2 (Arc 1) ovos por planta em um dos lotes avaliados, que continha 10 genótipos de feijoeiro. Quanto ao número de ovos por unidade de área nos mesmos genótipos desse lote, constatou-se uma variação de 0,7 e 9,4 ovos $/ \mathrm{cm}^{-2}$. No segundo lote avaliado, que continha 11 genótipos, a média de ovos por planta variou de 82,2 (G13028) a 1831,3 (Bolinha) e de 0,9 a 11,8 ovos $/ \mathrm{cm}^{-2}$ nos mesmos genótipos, respectivamente.

Confrontando os resultados do teste de não-preferência para oviposiçáo com chance de escolha e o de atratividade para adultos (Tabela 1), os genótipos ARC-3 e Canário 101 se mostraram em ambos como os mais preferidos. Já 'IAC-Centauro', 'MD Aurora', G2333, 'IACAlvorada', 'BRS Horizonte' e 'IAPAR-57' se destacaram como os menos preferidos para oviposiçáo e menos atrativos aos adultos. Diante desses resultados, pode-se sugerir que tais genótipos apresentam características que podem afetar o crescimento de populaçôes da mosca-branca e, portanto, devem ser incluídos nos estudos relacionados a programas de melhoramento visando à obtenção de cultivares de feijoeiro com resistência a insetos.

No teste sem chance de escolha não foram observadas diferenças entre as médias de ovos nos diferentes genótipos. As médias variaram de $3,7 \mathrm{ovos} / \mathrm{cm}^{-2} \mathrm{em}$ 'Canário 101 ' a 6,0 ovos $/ \mathrm{cm}^{-2}$ em 'IAC-Centauro' (Tabela 2). Embora a proporção de adultos por planta tenha sido a mesma (100 adultos/planta) que no teste com chance de escolha, observou-se redução significativa no número médio de ovos no teste sem chance de escolha (Tabelas 1 e 2). 
Tabela 2. Número médio de ovos por $\mathrm{cm}^{2}( \pm \mathrm{EP})$ de Bemisia tabaci biótipo $\mathrm{B}$ na face abaxial de folíolos de genótipos de feijoeiro em teste sem chance de escolha, em casa de vegetação. $\mathrm{T}=24,7 \pm 0,22^{\circ} \mathrm{C}$; $\mathrm{UR}=82,3 \pm 1,72 \%$

\begin{tabular}{lc|}
\hline Genótipo & Número de ovos/cm \\
\hline Canário 101 & $3,7 \pm 0,8$ \\
\hline ARC-3 & $4,0 \pm 0,8$ \\
\hline MD Aurora & $4,1 \pm 1,0$ \\
\hline IAPAR-57 & $4,5 \pm 0,7$ \\
\hline BRS-Horizonte & $4,6 \pm 1,0$ \\
\hline IAC-Alvorada & $4,9 \pm 1,8$ \\
\hline IAC-Centauro & $6,0 \pm 2,1$ \\
\hline CV (\%) & 34,59 \\
\hline F & 0,322 \\
\hline P & 0,923 \\
\hline
\end{tabular}

Médias com diferenças não significativas pelo teste $\mathrm{F}(\mathrm{p}>0,05)$.

O fato de não se observar diferenças no número de ovos nos genótipos avaliados, quando submetidos ao teste sem chance de escolha, pode ser devido a vários fatores, que, segundo BLUA et al. (1995), ao interagirem, durante o confinamento, causam mudança de comportamento da mosca-branca, alterando sua preferência, visto as condiçôes de confinamento ser diferentes nos dois testes.

Essa não diferenciação de genótipos no teste sem chance de escolha após a obtenção de médias de oviposição significativamente diferentes em teste com chance de escolha com B. tabaci biótipo B também foi observada por ToRres et al. (2007), que avaliaram a oviposição dessa mosca-branca em genótipos de algodoeiro.

\section{Desenvolvimento ovo-adulto, viabilidade de ovos e emergência de adultos de B. tabaci biótipo B nos genótipos selecionados}

Não se observaram diferenças entre as médias de duração da fase de ovo nos genótipos avaliados, as quais variaram de 10,8 a 11,0 dias (Tabela 3). Entretanto, a duração dessa fase foi alongada por algum fator desconhecido, visto que, trabalhando em condiçôes ambientais semelhantes, outros autores observaram período médio de incubação de seis dias. O pedicelo, além de fixar o ovo à planta hospedeira, serve para absorver água, como descrito por Gameel (1974) e Byrne e Bellows Júnior (1991) e absorveria, como sugerido por Torres et al. (2007), também algum outro composto que poderia interferir no desenvolvimento embrionário.

Em trabalho desenvolvido por Mansaray e Sundufu (2009), em feijoeiros mantidos a $26,0 \pm 0,5{ }^{\circ} \mathrm{C}$ e UR de $70 \%-80 \%$, a fase de ovo teve duraçáo de 6,5 dias, resultado próximo ao obtido por Tsai e WANG (1996) que encontraram seis dias trabalhando com a cultivar Podsquad a $25 \pm 1{ }^{\circ} \mathrm{C}$, UR de $80 \%$ a $90 \%$ e fotoperíodo de $14: 10$. Eichelkraut e Cardona (1989), em condiçōes de campo $\left(24^{\circ} \mathrm{C}\right.$ e UR de $\left.70 \%\right)$, obtiveram duração de 5,4 dias para a fase de ovo e, em cultivo protegido $\left(26^{\circ} \mathrm{C}\right.$ e UR de $67 \%$ ), a duração observada foi de 5,1 dias. VILlas BôAs et al. (2002), avaliando o potencial biótico da mosca-branca em diferentes espécies de plantas cultivadas, a $28 \pm 2{ }^{\circ} \mathrm{C}$, UR de $70 \pm 10 \%$ e fotofase de 14 horas, obtiveram uma duração de 6,1 dias para a fase de ovo em feijoeiro 'Carioquinha'.

A duração da fase ninfal também não apresentou diferenças entre os genótipos avaliados, variando de 16 dias ('IAC-Centauro') a 17,9 dias ('BRS-Horizonte'). No entanto, para os genótipos ARC-3, 'IAC-Alvorada' e 'Canário 101' náo foi possível a avaliação da duração dessa fase, pois o primeiro ocasionou $100 \%$ de mortalidade de ninfas e, nos outros dois, somente duas ninfas, em cada um deles, atingiram a fase adulta. Dessa forma, para esse parâmetro biológico, esses genótipos não foram incluídos na análise estatística (Tabela 3).

Também trabalhando com feijoeiro, outros autores obtiveram, para a fase ninfal, durações de 21,4 e 19 dias em campo e em cultivo protegido (Eichelkraut e Cardona, 1989), 14,94 dias (Tsai e WANG, 1996) e 14,69 dias (Mansaray e Sundufu, 2009). Oriani et al. (2005a) obtiveram para o período ninfal de $B$. tabaci biótipo $\mathrm{B}$ criada em diferentes genótipos de feijoeiro, uma duração que

Tabela 3. Duraçáo das fases de ovo, de ninfa e período ovo-adulto e viabilidade de ovos e emergência de adultos de Bemisia tabaci biótipo $\mathrm{B}$ em genótipos de feijoeiro, em casa de vegetação. $\mathrm{T}=25,4 \pm 0,2{ }^{\circ} \mathrm{C} ; \mathrm{UR}=82,2 \pm 0,9 \%$

\begin{tabular}{|c|c|c|c|c|c|c|}
\hline \multirow{3}{*}{$\begin{array}{l}\text { Genótipo } \\
\text { ARC-3 }\end{array}$} & \multicolumn{3}{|c|}{ Duração (dias)* } & \multirow{2}{*}{ Viabilidade de ovos (\%) } & \multirow{2}{*}{\multicolumn{2}{|c|}{ Emergência de adultos $(\%)^{* *}$}} \\
\hline & \multirow{2}{*}{$\begin{array}{c}\text { Ovo } \\
10,8 \pm 0,1\end{array}$} & \multirow{2}{*}{ Ninfa } & \multirow{2}{*}{$\begin{array}{c}\text { Ovo-adulto } \\
\text {----*** }^{*}\end{array}$} & & & \\
\hline & & & & $100 \pm 0,0$ & $0,0 \pm 0,0$ & $\mathrm{a}$ \\
\hline IAC-Alvorada & $10,9 \pm 0,1$ & $---* * *$ & $--{ }^{* * *}$ & $100 \pm 0,0$ & $3,3 \pm 0,0$ & $\mathrm{a}$ \\
\hline Canário 101 & $11,0 \pm 0,1$ & $---* * *$ & $---* * *$ & $100 \pm 0,0$ & $3,3 \pm 0,0$ & $\mathrm{a}$ \\
\hline BRS-Horizonte & $11,0 \pm 0,0$ & $17,9 \pm 0,7$ & $28,9 \pm 0,7$ & $100 \pm 0,0$ & $30,0 \pm 0,1$ & $b$ \\
\hline IAC-Centauro & $10,9 \pm 0,1$ & $16,0 \pm 0,7$ & $26,9 \pm 0,6$ & $100 \pm 0,0$ & $43,3 \pm 0,1$ & bc \\
\hline MD Aurora & $10,8 \pm 0,1$ & $17,0 \pm 0,5$ & $27,6 \pm 0,5$ & $100 \pm 0,0$ & $50,0 \pm 0,1$ & bc \\
\hline IAPAR-57 & $10,9 \pm 0,1$ & $16,2 \pm 0,4$ & $27,1 \pm 0,4$ & $100 \pm 0,0$ & $61,7 \pm 0,1$ & c \\
\hline CV (\%) & 5,82 & 17,17 & 10,13 & -- & 14,22 & \\
\hline $\mathrm{F}$ & 0,579 & 1,984 & 2,265 & -- & 5,589 & \\
\hline$P$ & 0,747 & 0,121 & 0,085 & -- & 0,012 & \\
\hline
\end{tabular}

${ }^{*}$ Médias ( $\left.\pm \mathrm{EP}\right)$ com diferenças năo significativas pelo teste $\mathrm{F}(\mathrm{p}>0,05)$. ** Médias seguidas pela mesma letra na coluna não diferem entre si pelo teste de Tukey $(\mathrm{p}>0,05)$.

***Número de repetiçóes insuficiente para avaliação (mínimo de $25 \%$ de sobrevivência). 
variou de 13,3 dias no genótipo B. Porrillo 70 a 18,8 dias, em Arc 3s.

Para o período de ovo a adulto, as médias também náo se diferenciaram. A variação observada foi de 26,9 dias ('IAC-Centauro') a 28,9 dias ('BRS-Horizonte'). Em pesquisa realizada por OrIANI et al. (2005a), com o mesmo biótipo de $B$. tabaci criado em diversos genótipos de feijoeiro, as médias de duraçáo do período de ovo a adulto variaram de 21 dias (B. Porrillo 70) a 26,5 dias (Arc 3s). Os autores sugeriram, para o genótipo Arc 3s, a presença de resistência do tipo não-preferência para alimentação e/ou antibiose por acarretar prolongamento na duração desse período. VILlas BôAS et al. (2002) obtiveram duração do período ovo-adulto de 21,9 dias em feijoeiro 'Carioquinha'. Tsar e WANG (1996) também constataram média inferior (20,95 dias) para a duração desse período. Nos trabalhos de Coudriet et al. (1985) e Mansaray e Sundufu (2009), as médias obtidas também foram mais baixas, constatando-se 21,8 e 21,19 dias respectivamente. Essas médias inferiores às obtidas no presente trabalho, provavelmente, devem-se às diferenças de germoplasma avaliado.

Pode-se observar forte influência da duração do período embrionário na duraçáo do período ovo-adulto, nos genótipos em que se constatou a emergência de adultos. Observou-se também, que algum fator de resistência causou a alta mortalidade das ninfas nos genótipos ARC-3, 'IAC-Alvorada' e 'Canário 101', fazendo-se necessários outros estudos para determinação dessa fonte de resistência. Resultado semelhante foi obtido por OrIani et al. (2008) para Arc 3s (genótipo selvagem), com 26,5 dias de duraçáo da fase jovem e mortalidade de 96\%.

A viabilidade da fase de ovo não foi afetada pelo genótipo onde os ovos se desenvolveram, sendo de 100\% em todos os genótipos estudados (Tabela 3). Avaliando a viabilidade de ovos de B. tabaci biótipo B em plantas de berinjela, tomateiro, batata-doce, pepino e feijoeiro, Tsai e WANG (1996) obtiveram média de 95,3\% em feijoeiro e médias variando de $94,5 \%$ a $96 \%$ para as demais espécies de plantas. Resultado divergente foi observado

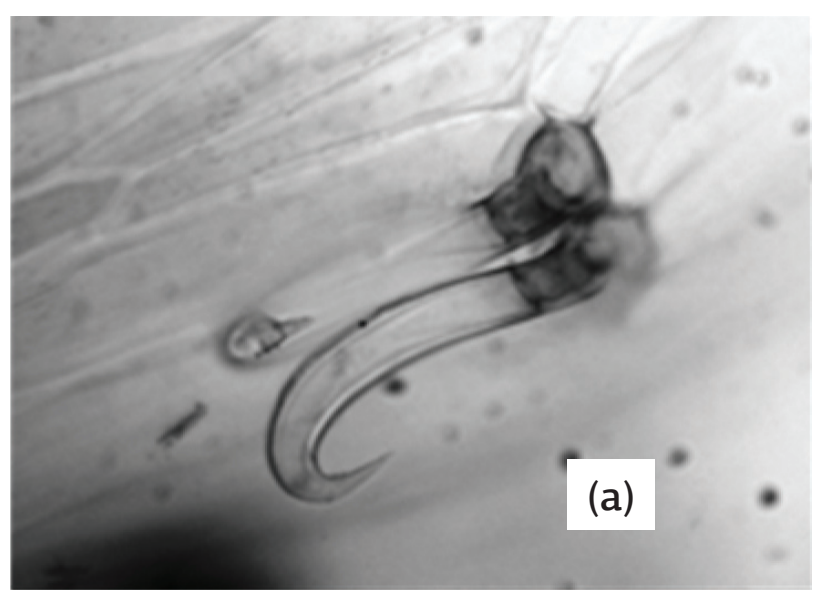

por Mansaray e Sundufu (2009) em feijoeiro, que obtiveram a média de $38,85 \%$ de viabilidade de ovos. A viabilidade média de ovos em feijoeiros, observada por Oriani et al. (2005a), variou de 77,5\% (Arc 3s) a 85,4\% (Arc 5s), estando mais próxima do presente estudo.

Diferentemente da viabilidade de ovos, a emergência de adultos foi fortemente influenciada pelo genótipo de feijoeiro no qual a ninfa se alimentou. Foram observadas diferenças entre as médias, e o genótipo $\mathrm{ARC}-3$ não proporcionou o desenvolvimento completo da fase de ninfa, acarretando $100 \%$ de mortalidade dos imaturos, não diferindo das médias obtidas para 'IAC-Alvorada' e 'Canário 101', que propiciaram a emergência de apenas 3,3\% de adultos. 'BRS-Horizonte', 'IAC-Centauro', 'MD Aurora' e 'IAPAR-57' ocasionaram 30,0\%; 43,3\%; 50,0\% e 61,7\% de emergência, respectivamente (Tabela 3). Verifica-se, portanto, que os genótipos ARC-3, 'IAC-Alvorada' e 'Canário 101' podem apresentar um tipo de resistência por não-preferência para alimentação e/ou antibiose, visto a baixa porcentagem de adultos emergidos.

Outros autores obtiveram em feijoeiro, para o período de ovo a adulto, sobrevivências de 25,6\% (MANSARAY e Sundufu, 2009) e $45,8 \%$ (Tsai e Wang, 1996). Em trabalho desenvolvido por OrIANI et al. (2005a), a porcentagem de mortalidade da fase imatura variou de 56,0\% (B. Porrillo 70) a 96,0\% (Arc 3s).

\section{Tipo e número de tricomas e correlação com teste de preferência para oviposição}

Em todos os genótipos avaliados, observaram tricomas dos tipos tector unciforme (em forma de gancho) e glandular, presentes em maior ou menor densidade (Figura 1).

'Canário 101' se destacou com o maior número de tricomas tectores $\left(1209,6\right.$ tricomas $\left./ \mathrm{cm}^{-2}\right)$ entre os genótipos avaliados. 'BRS-Horizonte' foi o que proporcionou menor número de tricomas tectores $\left(181,44\right.$ tricomas $\left./ \mathrm{cm}^{-2}\right)$, mas não diferindo estatisticamente de 'IAC-Centauro', 'IACAlvorada’ e 'IAPAR-57’ (Tabela 4).

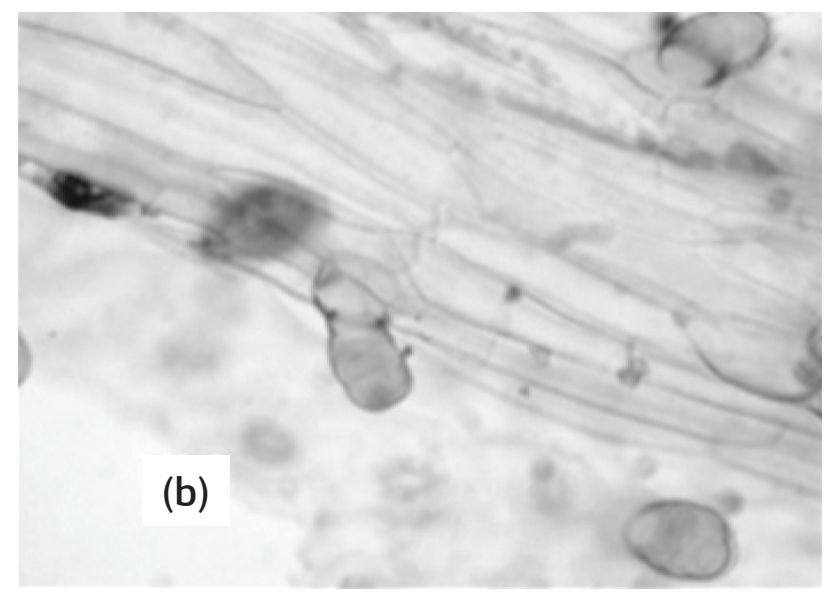

Figura 1. Tricomas em genótipos de feijoeiro: (a) Tricoma tector unciforme; (b) Tricoma glandular. 
Em trabalho de Oriani e LaRa (2000), o número médio de tricomas unciformes variou de 114,6 tricomas $/ \mathrm{cm}^{2}$ (IAPAR MD 808) a 790,1 tricomas $/ \mathrm{cm}^{-2}$ (Arc 5s). O genótipo Arc 5s, com 790,1 tricomas unciformes $/ \mathrm{cm}^{-2}$, foi o menos ovipositado nas quatro avaliaçôes feitas, com médias de 46,4; 7,2; 20,3 e 9,1 ovos por folíolos.

Quando se correlacionou o número de tricomas do tipo tector unciforme com o número de ovos colocados nos sete genótipos de feijoeiros selecionados pelo teste de preferência para oviposição com chance de escolha, obteve-se uma correlação classificada como positiva muito forte $(r=0,90)$, com coeficiente de correlação entre 0,90 e 1,00 . Dessa forma, pode se afirmar que a maior densidade de tricomas do tipo tector unciforme induziu maior preferência para oviposição por B. tabaci biótipo B. Podese supor que esse tipo de tricoma ofereça maior proteção aos ovos e ninfas contra potenciais inimigos naturais associados à praga. Segundo Heinz e Zalon (1995), o tipo, o comprimento e o arranjo espacial dos tricomas foliares podem influenciar na densidade populacional de mosca-branca em diversas culturas e, além disso, o fato de as moscas-brancas preferirem ovipositar próximo dos tricomas é devido à pressão de seleção exercida por inimigos naturais. Por outro lado, Oriani et al. (2005b) não constataram correlação entre o número de ovos $/ \mathrm{cm}^{-2}$ e o número total de tricomas (unciformes e aciculares) e tampouco entre o número de tricomas unciformes e aciculares, quando analisados separadamente.

As médias obtidas para o número tricomas do tipo glandular foram diferentes entre os materiais estudados (Tabela 4). Os genótipos IAPAR-57, BRS-Horizonte e IAC-Centauro proporcionaram as maiores médias de tricomas glandulares $\left(766,1 ; 745,9\right.$ e 705,6 tricomas $/ \mathrm{cm}^{-2}$ respectivamente); já nos genótipos 'Canário-101', 'IACAlvorada', 'MD Aurora' e ARC-3 houve menor número de tricomas desse tipo (Tabela 4).

Correlacionando o número de ovos colocados nas folhas dos sete genótipos de feijoeiro selecionados pelo teste de preferência para oviposição com chance de escolha e

Tabela 4. Número médio de tricomas $( \pm \mathrm{EP})$ em folíolos de cultivares de feijoeiro

\begin{tabular}{|c|c|c|c|c|}
\hline \multirow{2}{*}{$\begin{array}{l}\text { Genótipo } \\
\text { BRS-Horizonte }\end{array}$} & \multicolumn{2}{|c|}{$\begin{array}{l}\text { Número de tricomas } \\
\text { tectores unciformes } / \mathrm{cm}^{-2}\end{array}$} & \multicolumn{2}{|c|}{$\begin{array}{l}\text { Número de tricomas } \\
\text { glandulares } / \mathrm{cm}^{-2}\end{array}$} \\
\hline & $181,4 \pm 30,2$ & $\mathrm{a}$ & $745,9 \pm 72,6$ & $\mathrm{~b}$ \\
\hline IAC-Centauro & $221,8 \pm 26,2$ & $a b$ & $705,6 \pm 46,4$ & $b$ \\
\hline IAC-Alvorada & $302,4 \pm 36,3$ & $a b$ & $342,7 \pm 60,5$ & $\mathrm{a}$ \\
\hline IAPAR-57 & $322,6 \pm 26,2$ & $a b$ & $766,1 \pm 36,3$ & $b$ \\
\hline MD Aurora & $362,9 \pm 30,2$ & $b$ & $423,4 \pm 54,4$ & $\mathrm{a}$ \\
\hline ARC-3 & $383,0 \pm 22,2$ & $b$ & $463,7 \pm 46,4$ & $\mathrm{a}$ \\
\hline Canário-101 & $1209,6 \pm 68,5$ & c & $282,2 \pm 34,3$ & a \\
\hline CV (\%) & 27,31 & & 30,43 & \\
\hline $\mathrm{F}$ & 89,183 & & 15,530 & \\
\hline$P$ & 0,000 & & 0,000 & \\
\hline
\end{tabular}

Médias seguidas pela mesma letra, na coluna, não diferem entre si pelo teste de Tukey ( $p>0,05)$. o número de tricomas do tipo glandular presentes nesses genótipos, obteve-se uma correlação do tipo negativa moderada $(\mathrm{r}=0,58)$. Assim, à medida que se aumentou a densidade de tricomas glandulares nos genótipos, houve redução no número de ovos colocados por $B$. tabaci biótipo $B$, indicando que a presença desse tipo de tricoma em densidades mais elevadas conferiu à planta resistência do tipo não-preferência para oviposição.

\section{CONCLUSÃO}

Os genótipos 'IAC-Centauro', 'MD Aurora' e G2333 são os menos atrativos aos adultos de B. tabaci biótipo B. Em 'BRS-Horizonte', 'IAC-Centauro', 'MD Aurora', 'IACAlvorada' e 'IAPAR-57' observou-se menor oviposição por B. tabaci biótipo B em teste com chance de escolha. A emergência de adultos é negativamente influenciada por ARC-3, 'IAC-Alvorada' e 'Canário-101'.

\section{AGRADECIMENTOS}

Ao Conselho Nacional de Desenvolvimento Científico e Tecnológico - CNPq, pela concessão de bolsa de doutorado ao primeiro autor e à Fundação de Amparo à Pesquisa do Estado de Minas Gerais - Fapemig, pelos recursos para o desenvolvimento do projeto.

\section{REFERÊNCIAS}

ALMEIDA, L.D.; PEREIRA, J.C.V.N.A.; RONZELLI JÚNIOR, P.; COSTA, A.S. Avaliação de perdas causadas pelo mosaico dourado do feijoeiro (Phaseolus vulgaris) em condiçôes de campo. Fitopatologia Brasileira, v.9, p.213-219, 1984.

AZAEL, A. Numerical characterization of the development of the bean plant (Phaseolus vulgaris L.). Turrialba, v.26, p.209-210, 1976.

BLUA, M.J.; YOSHIDA, H.A.; TOSCANO, N.C. Oviposition preference of two Bemisia species (Homoptera: Aleyrodidae). Environmental Entomology, v.24, p.88-93, 1995.

BIANCHINI, A.; HOHMANN, C.L.; ALBERINI, J.L. Distribuição geográfica e orientaçôes técnicas para a prevenção do mosaico dourado do feijoeiro do Paraná. Curitiba: IAPAR, 1981. 3p. (Informe de Pesquisa, 5)

BYRNE, D.N.; BELLOWS JUNIOR, T.S. Whitefly biology. Annual Review of Entomology, v.36, p.431-457, 1991.

CARBONELL, S.A.M.; CHIORATO, A.F.; CARVALHO, C.L.R.; BENCHIMOL, L.L.; BERALDO, A.L.A.; GONÇALVES, J.G.R.; TICELI, M.; SOUZA, P.S.; GALLO, P.B. IAC Galante and IAC Centauro: special common bean types. Crop Breeding and Applied Biotechnology, v.8, p.177-180, 2008a. 
CARBONELL, S.A.M.; CHIORATO, A.F.; ITO, M.F.; PERINA, E.F.; GONÇALVES, J.G.R.; SOUZA, P.S.; GALLO, P.B.; TICELI, M.; COLOMBO, C.A.; AZEVEDO FILHO, J.A. IAC Alvorada and IAC Diplomata: new common bean cultivars. Crop Breeding and Applied Biotechnology, v.8, p.163-166, 2008b.

COCHRAN, G.W.; COX, G.M. Experimental designs. 2.ed. New York: J.Wiley, 1992. 640p.

COUDRIET, D.L.; PRABHAKER, N.; KISHABA, A.N.; MEYERDIRK, D.E. Variation in developmental rate on different hosts and overwintering of the sweetpotato whitefly, Bemisia tabaci (Homoptera: Aleyrodidae). Environmental Entomology, v.14, p.516-519, 1985.

EICHELKRAUT, K.; CARDONA, C. Biología, cria massal y aspectos ecológicos de la mosca blanca Bemisia tabaci (Gennadius) (Homoptera: Aleyrodidae), como plaga del frijol comun. Turrialba, v.39, p.51-55, 1989.

FARIA, J.C.; ANJOS, J.R.N.; COSTA, A.F.; SPERÂNDIO, C.A.; COSTA, C.L. Doenças causadas por vírus e seu controle. In: ARAÚJO, R.D.; RAVA, C.A.; STONE, L.F.; ZIMMERMANN, M.J.O. (Ed.). Cultura do feijoeiro comum no Brasil. Piracicaba: Potafos, 1996. p.731-769.

FONTES, F.H.M; COLOMBO, C.A; LOURENÇÃO, A.L. Caracterização molecular e divergência genética de Bemisia tabaci (Genn.) (Hemiptera: Aleyrodidae) em diferentes culturas e locais de cultivo. Neotropical Entomology, v.39, p.221-226, 2010.

GAMEEL, O.I. Some aspects of the mating and oviposition behavior of the cotton whitefly Bemisia tabaci (Genn.). Revue de Zoologie et de Botanique Africaine, v.88, p.784-788, 1974.

HEINZ, K.M.; ZALOM, F.G. Variation in trichome-based resistance to Bemisia argentifolii (Homoptera: Aleyrodidae) oviposition on tomato. Journal of Economic Entomology, v.88, p.1494-1502, 1995.

KOEHLER, H.S. Estatística experimental. Curitiba: UFPR, 1999. 124p.

MANSARAY, A.; SUNDUFU, A.J. Oviposition, development and survivorship of the sweetpotato whitefly Bemisia tabaci on soybean, Glycine max, and the garden bean, Phaseolus vulgaris. Journal of Insect Science, v.9, p.1-6, 2009.
ORIANI, M.A.G.; LARA, F.M. Oviposition preference of Bemisia tabaci (Genn.) biotype B (Homoptera: Aleyrodidae) for bean genotypes containing arcelin in the seeds. Anais da Sociedade Entomológica do Brasil, v.29, p.573-582, 2000.

ORIANI, M.A.G.; VENDRAMIM, J.D.; BRUNHEROTTO, R. Atratividade e não-preferência para oviposição de Bemisia tabaci (Genn.) biótipo B (Hemiptera: Aleyrodidae) em genótipos de feijoeiro. Neotropical Entomology, v.34, p.105-111, 2005a.

ORIANI, M.A.G.; VENDRAMIM, J.D.; BRUNHEROTTO, R. Influência dos tricomas na preferência para oviposição de Bemisia tabaci (Genn.) biótipo B (Hemiptera: Aleyrodidae) em genótipos de feijoeiro. Neotropical Entomology, v.34, p.97-103, 2005b.

ORIANI, M.A.G.; VENDRAMIM, J.D.; BRUNHEROTTO, R. Aspectos biológicos de Bemisia tabaci (Genn.) biótipo B (Hemiptera: Aleyrodidae) em seis genótipos de feijoeiro. Neotropical Entomology, v.37, p.191-195, 2008.

R DEVELOPMENT CORE TEAM. R: a language and environment for statistical computing. Vienna: R Foundation for Statistical Computing, 2009. Disponível em: <http://www.Rproject.org >. Acesso em: 28/12/2009.

TORRES, L.C.; SOUZA, B.; AMARAL, B.B.; TANQUE, R.L. Biologia e não-preferência para oviposição por Bemisia tabaci (Gennadius) biótipo B (Hemiptera: Aleyrodidae) em cultivares de algodoeiro. Neotropical Entomology, v.36, p.445-453, 2007.

TSAI, J.H.; WANG, K. Development and reproduction of Bemisia argentifolii (Homoptera: Aleyrodidae) on five host plants. Environmental Entomology, v.25, p.810-816, 1996.

TOSCANO, L.C.; BOIÇA JUNIOR, A.L.; MARUYAMA, W.I. Nonpreference of whitefly for oviposition in tomato genotypes. Scientia Agricola, v.59, p.677-681, 2002.

VILLAS-BÔAS, G.L.; FRANÇA, F.H.; MACEDO, N. Potencial biótico da mosca-branca Bemisia argentifolii a diferentes plantas hospedeiras. Horticultura Brasileira, v.20, p.71-79, 2002.

YOKOYAMA, M. Principais pragas e seu controle. In: ARAÚJO, R.D. (Ed.). Cultura do feijoeiro comum no Brasil. Piracicaba: Potafos, 1996. p.771-783. 